Document downloaded from:

http://hdl.handle.net/10251/38145

This paper must be cited as:

Samper; M.D.; Fages, E.; Fenollar, O.; Boronat, T.; Balart, R. (2013). The Potential of Flavonoids as Natural Antioxidants and UV Light Stabilizers for Polypropylene. Journal of Applied Polymer Science. 129(4):1707-1716. doi:10.1002/app.38871.

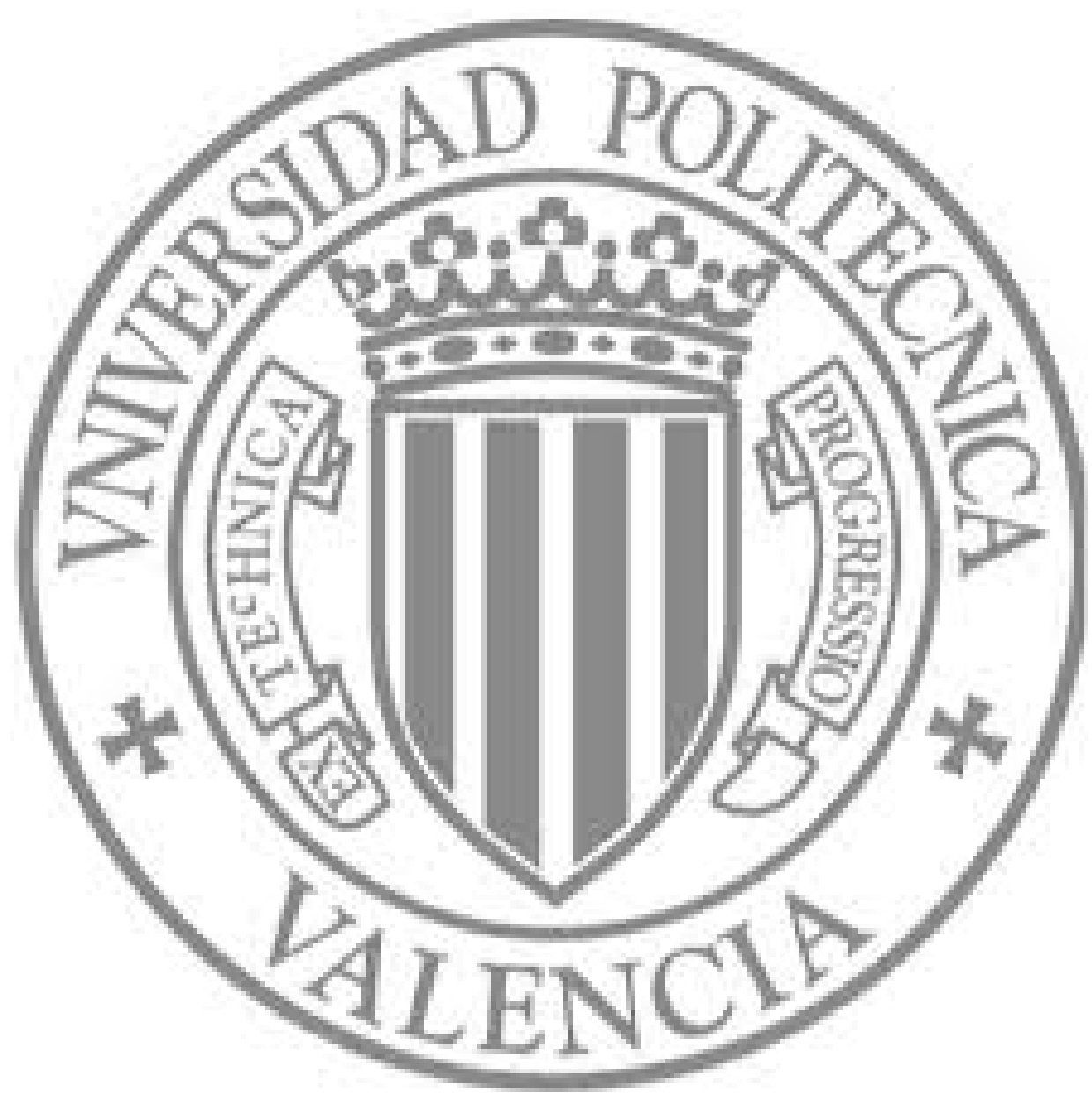

The final publication is available at

http://onlinelibrary.wiley.com/doi/10.1002/app.38871/abstract;jsessionid=047063166288351/

Copyright Wiley 


\section{The potential of flavonoids as natural antioxidants and UV light stabilizers for polypropylene}

M.D. Samper ${ }^{a^{*}}$, E. Fages ${ }^{\mathrm{b}}$, O. Fenollar ${ }^{\mathrm{a}}, \mathrm{T}$. Boronat ${ }^{\mathrm{a}}$ and R. Balart ${ }^{\mathrm{a}}$

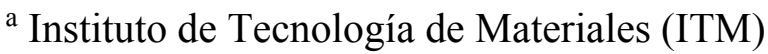

Universitat Politècnica de València (UPV).

Plaza Ferrándiz y Carbonell s/n, 03801, Alcoy, Alicante, Spain

b Textile Research Institute (AITEX)

Plaza Emilio Sala 1, 03801, Alcoy, Alicante, Spain

* Corresponding author: Tel.: 966528433; Fax: 966528433

E-mail adress: masammad@upvnet.upv.es

Postal adress: Plaza Ferrándiz y Carbonell s/n, 03801, Alcoy, Alicante, Spain

\section{ABSTRACT}

This paper presents a study on the stabilization of polypropylene (PP) against thermo-oxidation and UV radiation by using natural phenolic compounds derived from structures of flavonoids: a flavone (chrysin), a flavanol (quercetin), two flavanone glycosides (hesperidin and naringin) and flavanoligand (silibinin). Thermal stabilization has been assessed in an oxidizing atmosphere by means of differential scanning calorimetry (DSC) both in isothermal as well as dynamic conditions. In addition, the effectiveness of these phenolic compounds as thermal stabilizers at high temperature 
has been quantified with the use of thermogravimetric analysis (TGA). Stabilization against UV radiation has been estimated by studying the morphology changes of the exposed surfaces by scanning electron microscopy (SEM); also surface chemical changes have been followed by infrared spectroscopy (FTIR). Global results show that flavonoid compounds of type flavonols (quercetin and silibinin) provide the best results in stabilizing both against oxidation and against the action of UV radiation.

KEY WORDS: Flavonoids, antioxidant, polypropylene, ultraviolet light stabilizers

\section{INTRODUCTION}

Polymers in general and, especially polyolefins are highly sensitive to degradation processes when exposed to oxidant atmospheres and UV light. So that, industrial formulations require the addition of antioxidants and light stabilizers in order to preserve their physical and mechanical properties for long periods. Polypropylene (PP) in particular may undergo degradation during processing at typical processing conditions (around $200{ }^{\circ} \mathrm{C}$ ) or because of its use in adverse conditions, i.e. in the presence of light, heat or chemicals.

Antioxidants and UV stabilizers are used to inhibit the loss of physical properties and the subsequent increase in fragility. Because of environmental awareness and mainly to food safety considerations, the search for new additives in polymers has been stimulated in the last years.

The regulations of the European Union $n^{\circ} 10 / 2011$ defines the use of additives in food packaging, because during the processing or storage of these materials, additives can migrate from the containers and packaging to the food, and for this reason many studies on the use of natural antioxidants to prevent the contact of food with synthetic 
antioxidants have been carried out in recent years; it is important to remark the excellent results obtained with $\alpha$-tocopherol at low concentrations $(0.1$ to $2 \%)$ for the stabilization of polyolefins ${ }^{1-4}$; carnosic acid has also been used $(0.125,0.25,0.50$ and $0.75 \%)$ to delay the thermal oxidation of $\mathrm{PP}^{5}$; on other hand the use of small additions ( $\left.1 \mathrm{wt} . \%\right)$ of essential oils of oregano, savory and cinnamon to alginate-polycaprolactone copolymer has given interesting stabilizing properties ${ }^{6}$ as well as the use of essential oils of basil and thyme to provide higher stability to chitosan films has been reported ${ }^{7}$. Flavonoids represent a generic group of natural compounds with attracting potential in polymer stabilization due to presence of phenolic compounds in their structure. Their suitability for UV protection and antioxidation in plants is well known and this has led to the use of these compounds to prevent human aging. Phenolic compounds derived from flavonoids such as quercetin and catechin have been successfully used to delay oxidation on polyolefins ${ }^{1,8}$ and ethylene-vinyl alcohol copolymers $(\mathrm{EVOH})^{9}$. Among the wide variety of flavonoids, flavonols and flavanols have been reported to be the most efficient antioxidant compounds. Quercetin is a flavonol found in red onion ${ }^{10}$, tea $^{8}$, grapes $^{11}$, etc. and it has successfully been used as an antioxidant in low-density polyethylene (LDPE) ${ }^{1}$ increasing thermal stability with small additions of about 0.20 wt.\%. The potential of other flavonoids as antioxidant and/or UV stabilizers could be interesting to the polymer industry. For example, silibinin is a flavonoligand that can be obtained from the seeds of milk thistle ${ }^{12}$, chrysin is a flavone which is found in the Passiflora caerulea ${ }^{13}$, hesperidin is a flavanone glycoside found mainly in skin and the white membrane of the citrus fruit ${ }^{14}$ and naringin is also a flavanone glycoside which is found in the grapefruit ${ }^{15}$. All these flavonoids could provide potential stabilization effects on polyolefins. Other phenolic compounds have been reported to provide attracting stabilizing effects on polyolefins. The use of 0.01 and $0.1 \mathrm{wt} . \%$ of 
hydroxytyrosol to stabilize PP in processing has also been studied since typical processing conditions of polypropylene (over $200^{\circ} \mathrm{C}$ ) are enough to start oxidation thus leading to yellowing and embrittlement ${ }^{16}$.

The use of natural antioxidants in polymers provides similar stabilizing properties to those of synthetic antioxidants (mainly phenolic types); in addition, they have low toxicity as many natural antioxidants are typical compounds used to protect human health. In this work several flavonoids (quercetin, silibinin, chrysin, hesperidin and naringin) were investigated as potential sources of antioxidants and UV light stabilizers for PP. Mixtures of PP with each one of the flavonoids were obtained by means of extrusion and their behaviour under UV light radiation and thermo-oxidative behavior were analyzed. Differential scanning calorimetry (both isothermal and dynamic) and thermogravimetric analysis were used to characterize the antioxidant efficiency of each flavonoid. With regard to UV stabilizing effect, chemical changes were followed by infrared spectroscopy and surface changes (microcrack formation) were studied by scanning electron microscopy.

\section{EXPERIMENTAL}

\section{Materials and sample preparation.}

The polypropylene used in this study was a commercial grade Moplen HP648T of LyondellBasell (Basell Poliolefinas Ibérica, S.L., Barcelona, Spain) with a melt flow rate (MFR) of $53 \mathrm{~g} / 10 \mathrm{~min}\left(230^{\circ} \mathrm{C} / 2.16 \mathrm{~kg}\right)$ which is suitable for injection molding. Different flavonoids were used as stabilizer additives for polypropylene: quercetin, silibinin, chrysin, hesperidin and naringin and they all were supplied by Sigma-Aldrich (Sigma-Aldrich, Schnelldorf, Germany); the molecular structures of all of them can be seen in Figure 1. 
Initially samples were prepared with $0.5 \mathrm{wt} . \%$ of the different types of flavonoids and subsequently, additional compositions with $0.25 \mathrm{wt} . \%$ and $0.75 \mathrm{wt} . \%$ were prepared with flavonoids with best results in the initial characterization. We used small percentages of flavonoids according to the literature review ${ }^{1,5,16}$.

Sample preparation was carried out by mixing in a hot-extrusion process with a co-rotating twin screw extruder supplied by Dupra (Dupra S.A., Castalla, Spain) at 190 ${ }^{\circ} \mathrm{C}$. Thermal characterization (DSC and TGA) was performed with the extruded pellet in order to evaluate the oxidative degradation. After that, sheets sizing $40 \times 40 \times 2 \mathrm{~mm}^{3}$ were injection molded with a Babyplast 6/6 (Cronoplast SL, Abrera, Spain) at $190{ }^{\circ} \mathrm{C}$. We have selected this temperature profile because PP is characterized by a relatively narrow processing range between $180-200{ }^{\circ} \mathrm{C}$ due to its high sensitiveness to thermaldegradation. So that, the use of $190^{\circ} \mathrm{C}$ as processing temperature is enough to provide good processing conditions and doesn't produce thermal degradation during processing.

Finally the aging treatment of materials was performed by using a high pressure mercury lamp (1000 W and $350 \mathrm{~nm}$ wavelength), model UVASPOT 1000RF2 (Honle Spain SA, Barcelona, Spain). The exposure period was varied from 0 to 6 hours.

\section{Thermal characterization.}

The thermogravimetric analysis (TGA) was held in a thermobalance mod. TGA/E 851e by Mettler Toledo (Mettler-Toledo, Schwarzenbach, Switzerland). Samples with a total weight in the 5-10 mg range were placed into alumina crucibles and subjected to a temperature program used from 30 to $700{ }^{\circ} \mathrm{C}$ at a heating rate of 10 ${ }^{\circ} \mathrm{C} \mathrm{min}{ }^{-1}$ in an oxygen atmosphere (flow rate of $50 \mathrm{~mL} \mathrm{~min}^{-1}$ ). The parameters analyzed were the $\mathrm{T}$ onset and the inflection point of the material degradation. The $\mathrm{T}$ onset was calculated as the intersection point between the tangents to the curve slope change, 
corresponding to the initial loss of mass. The inflection point is an interesting value to characterize a degradation process since it represents the temperature at wich, the maximum degradation rate occurs.

The calorimetric analysis was carried out using a DSC Mettler-Toledo cell 821 (Mettler-Toledo, Schwerzenbach, Switzerland). Samples with a total weight of about 5$10 \mathrm{mg}$ were placed into aluminum crucibles. To evaluate the antioxidant efficiency of the different flavonoids on polypropylene, two types of tests DSC were carried out. The first test was a dynamic program from 30 to $350{ }^{\circ} \mathrm{C}$ at a heating rate of $5^{\circ} \mathrm{C} \mathrm{min}{ }^{-1}$ in air atmosphere and the oxidative degradation was identified as the onset oxidation temperature (OOT). The second test was performed with a ramp from 30 to $210^{\circ} \mathrm{C}$ with a heating rate of $5^{\circ} \mathrm{C} \mathrm{min}^{-1}$ and after this, isothermal conditions were maintained at this temperature $\left(210^{\circ} \mathrm{C}\right)$ for $90 \mathrm{~min}$, in air atmosphere. This test allowed obtaining the degradation onset by determining the oxidation induction time (OIT).

The degree of crystallinity of the samples was calculated using the following equation:

$$
X_{c}(\% \text { Crystallinity })=\left[\Delta H_{f} / \mathrm{w} \Delta H_{f 100}\right] \times 100
$$

where $\Delta H_{f}$ is the latent heat of fusion of the sample, $\Delta H_{f 100}$ is the theoretical latent heat of fusion of a PP with $100 \%$ crystallinity $(207.1 \mathrm{~J} / \mathrm{g})^{17}$, and $\mathrm{w}$ is the weight fraction of PP in the sample.

DSC tests were also conducted to the UV aged samples; the test was performed with a temperature ramp from 30 to $350{ }^{\circ} \mathrm{C}$ at a heating rate of $5^{\circ} \mathrm{C} \mathrm{min}-1$ in a nitrogen atmosphere (flow rate $60 \mathrm{~mL}$ min-1) to avoid additional oxidations. In particular, changes in crystallinity were determined.

\section{Infrared spectroscopy (FTIR) analysis.}


Fourier transform infrared spectroscopy (FTIR) was performed on the aged samples using an infrared spectrometer Perkin-Elmer Spectrum BX (Perkin-Elmer Spain S.L., Madrid, Spain). 20 scans between 4000 and $600 \mathrm{~cm}^{-1}$ were performed with a resolution of $2 \mathrm{~cm}^{-1}$ in the reflection mode. PP molecular degradation was chatacterized by carbonyl index $(\mathrm{CI})^{18}$, wich was calculated by equation (1).

$$
\text { Carbonyl index }=\mathrm{A}_{\mathrm{c}} / \mathrm{A}_{\mathrm{R}}
$$

Where $A_{c}$ is the area of the carbonyl absorption band (from $1850-1650 \mathrm{~cm}^{-1}$ ) and $A_{R}$ is the area of the reference band $\left(2700-3000 \mathrm{~cm}^{-1}\right)$. The reference band was not affected by UV irradation.

\section{Morphological characterization.}

Surface characterization of the aged samples was performed using a scanning electron microscope (SEM), PhenomTM (FEI Company, Eindhoven, Nederland). Prior to sample observation a sputtering process was carried out with a gold-palladium alloy with a Sputter Coater EMITECH mod. SC7620 (Quorum Technologies Ltd, East Sussex, UK).

\section{RESULTS AND DISCUSSION}

\section{Characterization of the oxidative retardant effect of flavonoids}

The oxidative retardant effect of flavonoids was evaluated using thermal analysis; in Fig. 2 we can observe the dynamic calorimetric curves of samples with a 0.5 wt.\% of different flavonoids. It can be seen an endothermic melting peak of PP located about $170^{\circ} \mathrm{C}$. Over this, we can see an exothermic process which is directly related to thermo-oxidative degradation. In the case of the non-stabilized polypropylene, thermooxidation starts at $226.4{ }^{\circ} \mathrm{C}$, and the oxidative degradation of samples with $0.5 \mathrm{wt} . \%$ of hesperidin, naringin and chrysin occurs at a similar temperature. This indicates that 
these flavonoids have no significant oxidative retardant effect on polypropylene at this concentration. On other hand sample containing $0.5 \mathrm{wt} . \%$ silibinin delays the start of oxidative degradation about $25^{\circ} \mathrm{C}$ if compared to the non-stabilized polypropylene so that degradation starts at around $251.1^{\circ} \mathrm{C}$. With regard to the use of quercetin it is important to remark its extraordinary stabilization effect; the oxidation onset temperature (OOT) is remarkably increased up to values of about $259.3^{\circ} \mathrm{C}$, which represents a shift of $33^{\circ} \mathrm{C}$. Therefore silibinin and quercetin cause an oxidative retardant on polypropylene, since both they delay the onset of the thermal oxidation. This is a consequence of their chemical structure: a flavonol (quercetin) and a flavonoligand (silibinin) whose antioxidant properties in plants have been widely reported ${ }^{1,8}$. The isothermal calorimetric curves can be seen in Fig. 3 and it can be clearly detected that the oxidation induction time (OIT) for the non-stabilized polypropylene is about $8 \mathrm{~min}$. The addition of $0.5 \mathrm{wt} . \%$ of the different flavonoids leads to an increase in the oxidation induction time (OIT) values; so that, the OIT values for the stabilized formulations are $7.9,10.9,11.1,16.7$ and 81.4 min for hesperidin, naringin, chrysin, silibinin and quercetin respectively. Once again, these results indicate that only silibinin and quercetin to a greater extent, promote a remarkable increase in the stability of polypropylene against degradation. This effect may be due to the structure of these flavonoids (quercetin and silibinin) with more active $\mathrm{OH}$ groups in phenolic rings than other flavonoids selected (figure 1). Consistent with most polyphenolic antioxidants, both the configuration and total number of hydroxyl groups substantially influence several mechanisms of antioxidant activity. Free radical scavenging capacity is primarily attributed to the high reactivities of hydroxyl substituents that participate in the following reaction: ${ }^{19}$

$$
\mathrm{F}-\mathrm{OH}+\mathrm{R} \rightarrow \mathrm{F}-\mathrm{O}+\mathrm{RH}
$$


In addition, the difference in the OIT between these two compounds may be related to the size of the molecule, since quercetin molecule is smaller than silibinin and therefore quercetin molecule is characterized by higher chain mobility. As we have described before, phenolic compounds work as free radical scavengers. So that, when a free radical is formed as a consequence of thermo-oxidation, phenolic compounds move toward this unstable point to block further degradation thus producing a stabilization effect. In the case of hesperidin, the stabilization effect is almost negligible at this concentration and the use of naringin and chrysin slightly improves stability.

As it was noted that silibinin and, to a greater extent quercetin, delay the oxidative degradation of polypropylene, additional formulations containing $0.25 \mathrm{wt} . \%$ and $0.75 \mathrm{wt} . \%$ were prepared in order to evaluate the effect of the flavonoid content. Table 1 shows a summary of the main parameters obtained by isothermal and dynamic DSC characterization for polypropylene stabilized with different amounts of silibinin and quercetin in the $0.25-0.75 \mathrm{wt} . \%$ range.

In the case of samples with quercetin, the oxidative onset temperature (OOT) is similar for all compositions, with values around $260{ }^{\circ} \mathrm{C}$, but in isothermal conditions we observe a clear increasing tendency for oxidation onset temperatures as the quercetin content increases. With regard to silibinin, it is possible to detect some differences; the oxidation onset temperature (OOT) in dynamic conditions changes in the $238-250{ }^{\circ} \mathrm{C}$ range, reaching the maximum for compositions with $0.5 \mathrm{wt} . \%$. With regard to oxidation induction time (OIT) in isothermal conditions, the OIT value is similar for 0.25 and 0.50 wt.\% while the stability is highly improved for compositions with $0.75 \mathrm{wt} . \%$ since the OIT is increased up to the value of $84.0 \mathrm{~min}$.

The table 2 shows the thermogravimetric results of samples with different flavonoids. This information is useful to know the thermal stability in aggressive 
conditions; as the thermal stability increases, the characteristic TGA is moved to higher temperatures. If we take the onset temperature as a comparative value, the nonstabilized polypropylene is characterized by an onset temperature of $265.9^{\circ} \mathrm{C}$. With regard to samples containing $0.5 \mathrm{wt} . \%$ of silibinin and $0.5 \mathrm{wt} . \%$ quercetin, the onset temperature is moved to higher values $\left(289.0{ }^{\circ} \mathrm{C}\right.$ and $287.1{ }^{\circ} \mathrm{C}$ respectively) which is in agreement with previous results obtained by DSC. Although the use of 0.5 wt. $\%$ of chrysin and naringin promotes a significant increase in thermal stability of polypropylene (with degradation onset temperatures of about $278.9^{\circ} \mathrm{C}$ and $276.8^{\circ} \mathrm{C}$ ), their effectiveness is lower than the observed for quercetin and silibinin.

The results of thermogravimetric analysis of polypropylene stabilized with different percentages of quercetin and silibinin can also be seen in Table 2 . It can be observed that the samples containing $0.25 \mathrm{wt} . \%$ of quercetin show a remarkable higher stability than non-stabilized polypropylene and this thermal stability is not increased in a remarkable way for higher quercetin amounts. By contrast the increase in the percentage of silibinin reduces degradation; both the degradation onset temperature and the inflection point show a clear increasing tendency. This is in agreement with previous dynamic DSC results thus indicating that the antioxidant efficiency of quercetin is less sensitive to the total content as in the case of silibinin. It is important to remark that the stabilizing efficiency of a particular phenolic compound is directly related to its structure (number of hydroxyl groups, chain mobility, etc.). So that, each phenolic compound is characterized by an optimum amount which provides optimum stabilization effects. Addition of higher amounts (over the optimum point) do not provide higher stabilization and even, a decrease in the stabilization effects can be detected since other degradation mechanisms can be activated. 


\section{UV light stabilizing effect of flavonoids.}

PP is known to be sensitive to photo-degradation when exposed to sunlight or UV radiation in air, as well as at wavelengths of more than $300 \mathrm{~nm}$. Aging was performed by sample exposure to UV light with polypropylene formulations containing $0.5 \mathrm{wt} . \%$ of the different flavonoids, in order to evaluate the potential stabilizing effect against UV light of the natural phenolic compounds derived from flavonoids. UV aging was conducted for 6 hours and samples were tested after 2, 3, 5 and 6 hours.

The degradation in PP is an irreversible process in which, of is possible mechanisms, oxidation is usually dominant. The incorporation of one molecule of oxygen per hundred polymer chain repeat units can reduce the molecular weight by a factor of two or three, and lead to a total embrittlement of the polymer ${ }^{18}$. FTIR can provide valuable information on the polymer degradation kinetics and mechanisms by identifying the oxidation products. The carbonyl index (CI) is used for the indirect determination of the embrittlement time in polymers. The carbonyl absorbance intensity $\left(1850-1650 \mathrm{~cm}^{-1}\right)$ is compensated for by the ratio of its value to the intensity of an internal reference peak $(3000-2700)$.

Chemical changes related to the accelerated aging by UV light were analyzed by means of FTIR spectroscopy. Fig. 4 shows the FTIR absorbance spectra of the nonstabilized polypropylene at different aging times. We can see a clear increase in the intensity of absorption in the $1850-1650 \mathrm{~cm}^{-1}$ range, which is characteristic of the carbonyl group; if we take into consideration that the intensity of the carbonyl and hydroperoxide groups $\left(3000-3600 \mathrm{~cm}^{-1}\right)$ are commonly used to measure the amount of oxidation as described by other authors ${ }^{20,21}$ it is possible to evaluate the effectiveness of the different flavonoids by following the evolution of the carbonyl peak as in our case the increase of the hydroperoxide group is very low and very difficult to assess. 
The rest of the investigated samples show similar trends and main values are summarized in Table 3 using the carbonyl peak area of all the samples. It should be noted that the flavonoids have carbonyl groups in their structure. In order to calculate the increase in area caused by aging, we calculated the area of the carbonyl peak corresponding to the aging of each sample minus the carbonyl peak area of the material without aging.

It can be seen from Table 3 that once again samples with quercetin and silibinin aged for a total time of 6 hours show the highest UV light stabilizing effect as the area of the carbonyl group is smaller than that of the non-stabilized polypropylene. This indicates that these two flavonoids are suitable to stabilize polypropylene against UV light; on other hand the other flavonoids have similar carbonyl group area to that of non-stabilized polypropylene or a little higher.

In addition to surface chemical characterization by FTIR, the effects of the UV light aging was also studied by DSC; Table 4 shows that the crystallinity increases with the aging time in all samples.

The increase in crystallinity can be explained by a decrease in molecular size during aging, since the virgin material without aging has a high concentration of tangles that restrict chain crystallization during processing, and when exposed to UV radiation, chain scission occurs and subsequent oxidation. These reactions occur mainly in the amorphous region because of the greater permeability of oxygen. These areas remain free and then reordered to increase the crystallinity of the samples ${ }^{22}$.

We can also observe that samples containing silibinin and quercetin subjected to UV light aging for 6 hours show that the increment of crystallinity values is less than non-stabilized polypropylene with an exposure time to UV light of 6 hours; once again this is a clear evidence that indicates that these two flavonoids can also stabilize 
polypropylene against UV light, with greater intensity than the rest. Figure 5 shows DSC curves of the SIL $0.5 \%$ PP sample without exposure to UV light and 6 hours of exposure to UV light. We can clearly see that the latent heat of fusion is higher in the sample exposed to UV light which indicated higher crystallinity.

The morphological changes of the aged samples have also been studied by scanning electron microscopy (SEM). In Fig. 5 it can be seen how the non-stabilized polypropylene changes as the exposure time to UV light increases. Fig. 5a and Fig. 5b that correspond to exposure times of 0 and 2 hours respectively show a smooth surface without cracks; while in Fig. 5c the first cracks appear due to aging effects after 3 hours of UV exposure. As the exposure time to UV light increases, it is clearly detectable presence of more and higher in size as observed in Fig. 5d and Fig. 5e corresponding to samples with exposure times to UV light aging of 5 and 6 hours respectively. As we have described before, UV light promote chain scission and subsequent oxidation thus allowing rearrangement of polymer chains to increase crystallinity. This phenomenon is responsible for appearing internal stresses that lead to microcrack formation thus causing a material embrittlement ${ }^{23-25}$.

Fig. 6 shows SEM images of polypropylene formulations containing $0.5 \mathrm{wt} . \%$ of the different flavonoids as stabilizer additives, subjected to a UV light aging time of 3 hours. It is possible to observe that the sample containing naringin (Fig. 6a) and chrysin (Fig. 6b) show some cracks due to degradation. However samples with hesperidin, quercetin and silibinin show a clear smooth surface which is representative for slow or negligible UV light aging.

By contrast, samples exposed to UV light for a total period of 5 hours present numerous cracks as shown in Fig. 7, although in the case of samples with quercetin and silibinin, Fig. 7d and Fig. 7e respectively, there are less cracks than with the rest of the 
materials, thus indicating that quercetin and silibinin, additionally to the oxidative retardant effect, they can provide attracting stabilizing effects against UV light to polypropylene to a greater extent than the rest.

\section{CONCLUSIONS}

Flavonoids are well known for UV protection and antioxidation in plants due to presence of phenolic compounds in their structure and this has led to the use of these compounds to prevent human aging.

This work has allowed verifying and validating the usefulness of the flavonoids in the oxidation stabilization of polypropylene which is highly sensitive to thermooxidative degradation. Addition of small amounts of flavonoids contributes to the development of more environmental friendly formulations for this type of polymers, thus allowing full or partially replacement of petrochemical antioxidants. Furthermore it has been shown that within the group of flavonoids, the subgroup of flavonols (silibinin and quercetin) provide the best stabilizing results. These offer similar behavior to conventional petroleum-based phenolic antioxidants widely used in the stabilization of polyolefins.

Finally, it is important to remark that the composition ranges that provide good stabilizing effects are similar to those used in the industry with synthetic antioxidants offering very attractive possibilities for this set of natural compounds.

\section{ACKNOWLEDGEMENTS}

This work is part of the project IPT-310000-2010-037,"ECOTEXCOMP: Research and development of textile structures useful as reinforcement of composite materials with marked ecological character" funded by the "Ministerio de Ciencia e 
Innovacion", with an aid of 189540.20 euros, within the "Plan Nacional de Investigación Científica, Desarrollo e InnovaciónTecnológica 2008-2011” and funded by the European Union through FEDER funds, Technology Fund 2007-2013, Operational Programme on $\mathrm{R}+\mathrm{D}+\mathrm{i}$ for and on behalf of the companies.” Also, Generalitat Valenciana Ref: ACOMP/2012/087 is acknowledged for financial support. 


\section{REFERENCE}

1. Koontz, J. L.; Marcy, J. E.; O’Keefe, S. F.; Duncan, S. E.; Long, T. E.; Moffitt, R. D., J. Appl. Polym. Sci. 117, 22992010.

2. Mallegol, J.; Carlsson, D. J.; Deschenes, L., Polym. Degrad. Stabil. 73, 2592001.

3. Peltzer, M.; Wagner, J. R.; Jimenez, A., J. Therm. Anal. Calorim. 87, 4932007.

4. Strandberg, C.; Albertsson, A. C., J. Appl. Polym. Sci. 98, 24272005.

5. Jipa, S.; Zaharescu, T.; Setnescu, R.; Gorghiu, L. M.; Dumitrescu, C.; Santos, C.; Silva, A. M.; Gigante, B., J. Appl. Polym. Sci. 95, 15712005.

6. Salmieri, S.; Lacroix, M., J. Agric. Food Chem. 54, 102052006.

7. Bonilla, J.; Atares, L.; Vargas, M.; Chiralt, A., Food Hydrocolloids 26, 92012.

8. Dopico-Garcia, M. S.; Castro-Lopez, M. M.; Lopez-Vilarino, J. M.; Gonzalez-

Rodriguez, M. V.; Valentao, P.; Andrade, P. B.; Garcia-Garabal, S.; Abad, M. J., J. Appl. Polym. Sci. 119, 35532011.

9. Lopez-de-Dicastillo, C.; Alonso, J. M.; Catala, R.; Gavara, R.; Hernandez-Munoz, P., J. Agric. Food Chem. 58, 109582010.

10. Perez-Gregorio, R. M.; Garcia-Falcon, M. S.; Simal-Gandara, J.; Rodrigues, A. S.; Almeida, D. P. F., J. Food Compos. Anal. 23, 5922010.

11. Iacopini, P.; Baldi, M.; Storchi, P.; Sebastiani, L., J. Food Compos. Anal. 21, 589 2008.

12. Liu, H.; Du, X. L.; Yuan, Q. P.; Zhu, L., Phytochem. Anal. 20, 4752009.

13. Wolfman, C.; Viola, H.; Paladini, A.; Dajas, F.; Medina, J. H., Pharmacol. Biochem. Behav. 47, 11994.

14. Al-Ashaal, H. A.; El-Sheltawy, S. T., Pharm. Biol. 49, 2762011.

15. Sudto, K.; Pornpakakul, S.; Wanichwecharungruang, S., Int. J. Food Sci. Technol. 44, 17372009.

16. Peltzer, M.; Jimenez, A., J. Therm. Anal. Calorim. 96, 2432009.

17. Van Krevelen D. W. Properties of Polymer; Elsevier: New York, 1997; p 109.

18. Chandramouleeswaran, S.; Mhaske, S.T.; Kathe, A.A.; Varadarajan, P.V.; Prasad, V.; Vigneshwarab, N., Nanotechnology. 18, 3857022003.

19. Heim, K.E.; Tagliaferra, A.R.; Bobilya, D.J., J. Nutr. Biotech. 13, 5722002.

20. Gugumus, F., Polym. Degrad. Stabil. 62, 2351998.

21. Richaud, E.; Farcas, F.; Fayolle, B.; Audouin, L.; Verdu, J., Polym. Test 25, 829 2006.

22. Rabello, M. S.; White, J. R., Polymer 38, 63791997.

23. Rajakumar, K.; Sarasvathy, V.; Chelvan, A. T.; Chitra, R.; Vijayakumar, C. T., J. Appl. Polym. Sci. 123, 29682012.

24. Kaczmarek, H.; Oldak, D.; Malanowski, P.; Chaberska, H., Polym. Degrad. Stabil. 88, 1892005.

25. Yakimets, I.; Lai, D. W.; Guigon, M., Polym. Degrad. Stabil. 86, 592004. 


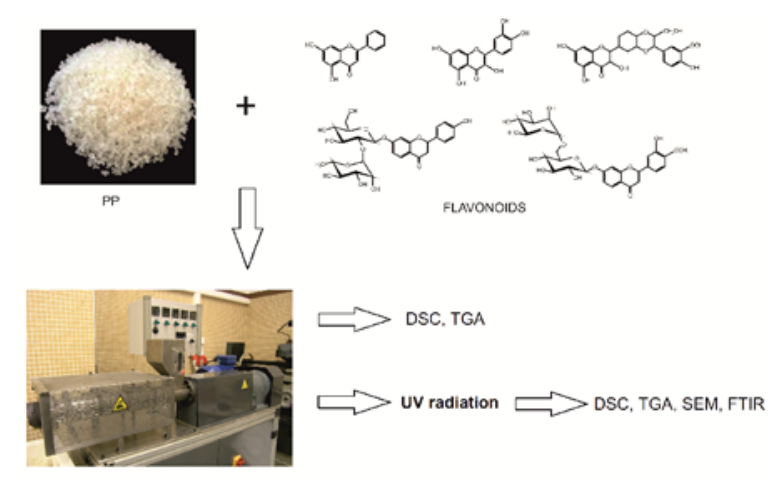

FIGURE ABSTRACT

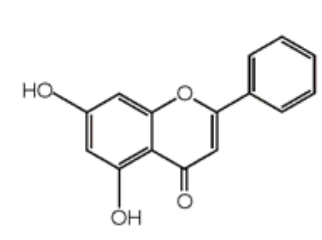

a)

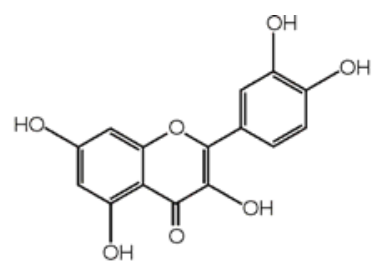

b)<smiles>COc1cc(C2OC3CC(C4Oc5cc(O)cc(O)c5C(=O)C4O)CCC3OC2CO)ccc1O</smiles>

c)

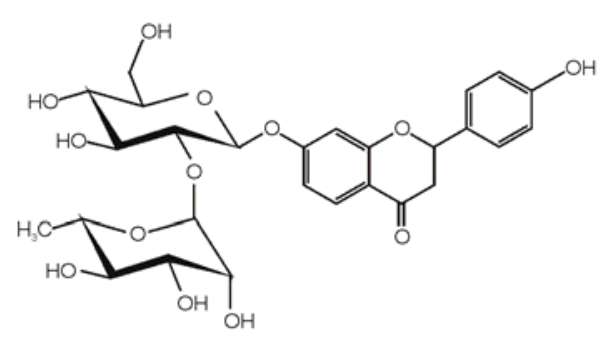

d)

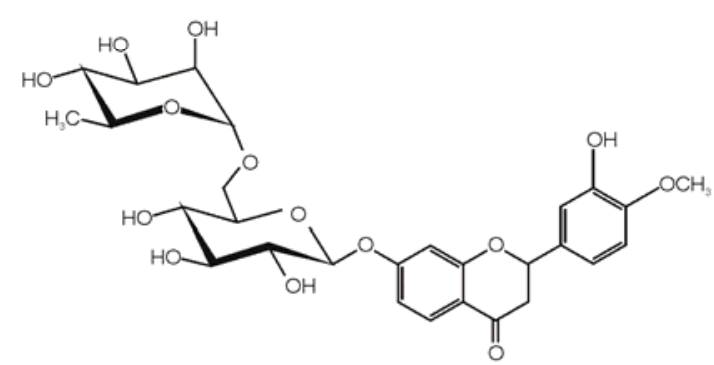

e)

FIGURE 1. Chemical structures of the flavonoids used in this study, a) chrysin, b) quercetin, c) silibinin A, d) naringin e) hesperidin. 


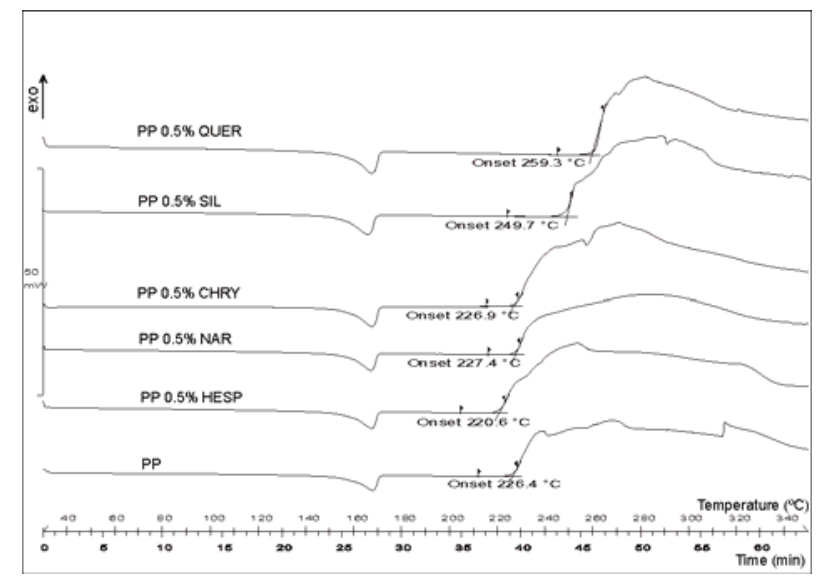

FIGURE 2. Dynamic DSC curves of polypropylene formulations containing $0.5 \mathrm{wt} . \%$ of different flavonoids.

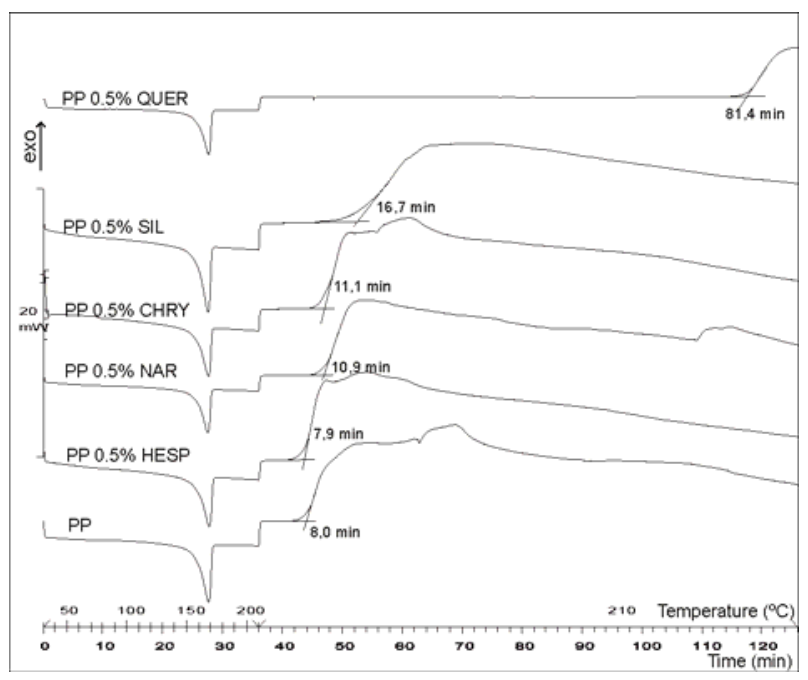

FIGURE 3. Isothermal $\left(210^{\circ} \mathrm{C}\right) \mathrm{DSC}$ curves of polypropylene formulations containing 0.5 wt. $\%$ of different flavonoids. 


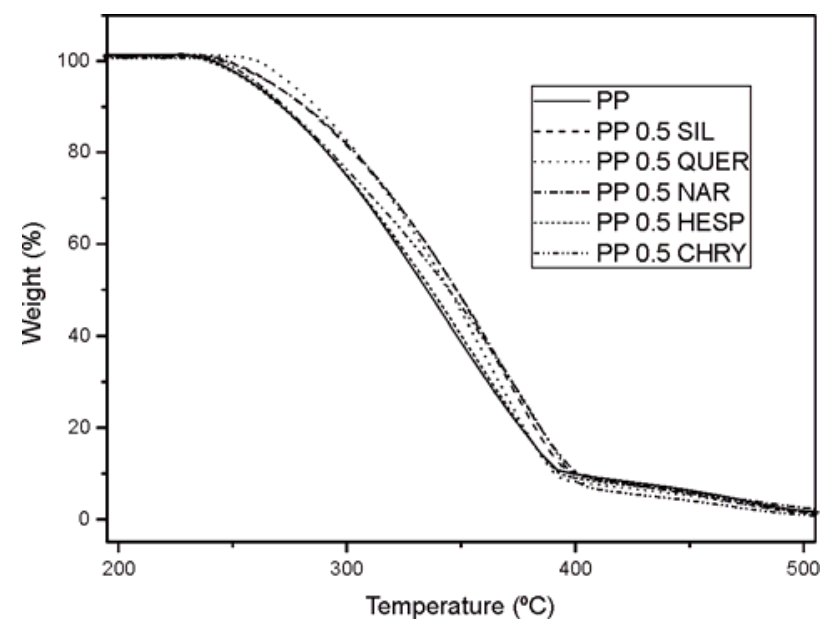

FIGURE 4. FTIR spectra of non-stabilized polypropylene subjected to UV light exposure for $0,2,3,5$ and 6 hours.

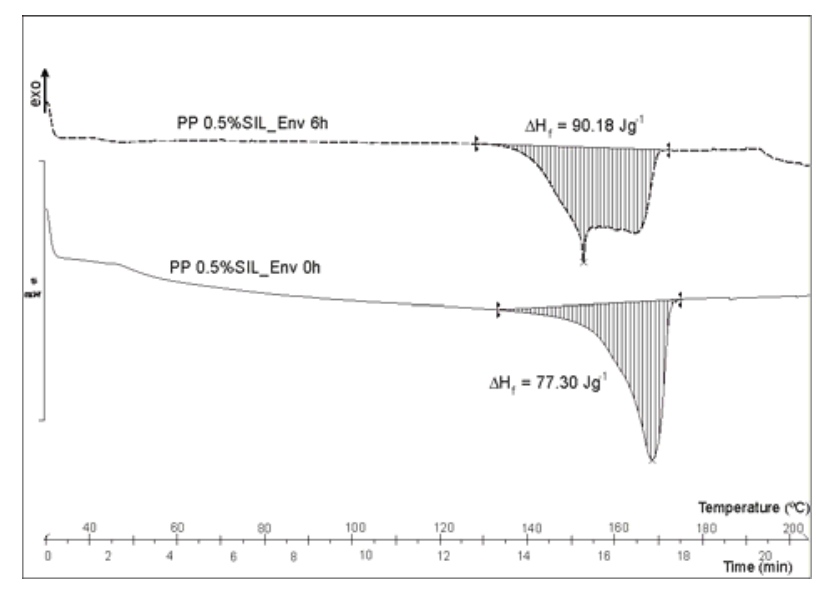

FIGURE 5. Dynamic DSC curves of the SIL 0.5\% PP sample without exposure to UV light and 6 hours of exposure to UV light. 


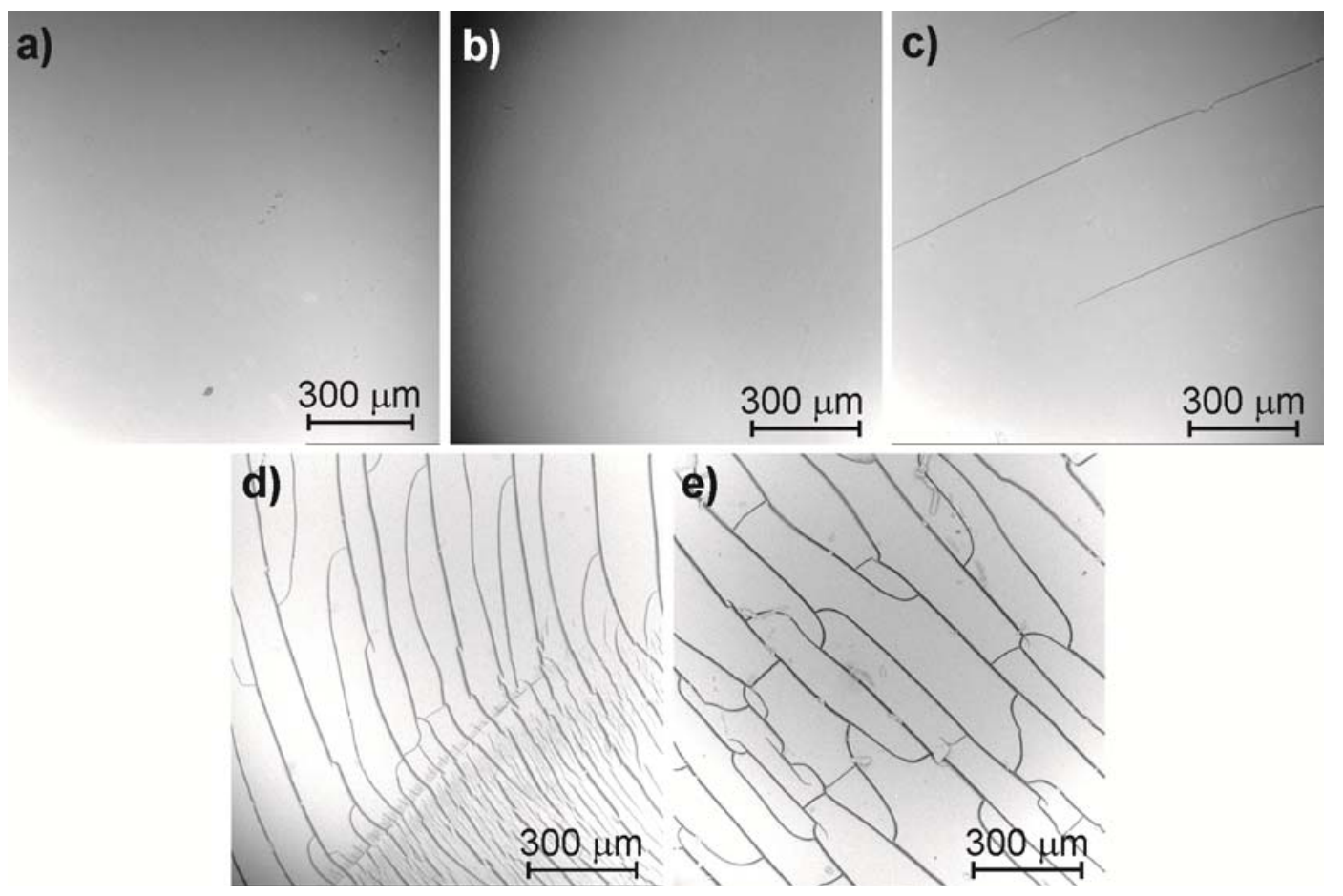

FIGURE 6. SEM images of non-stabilized polypropylene subjected to UV light aging process for different exposure times. A) $0 \mathrm{~h}$, b) $2 \mathrm{~h}$., c) $3 \mathrm{~h}$., d) $5 \mathrm{~h}$. and e) $6 \mathrm{~h}$. 
a)

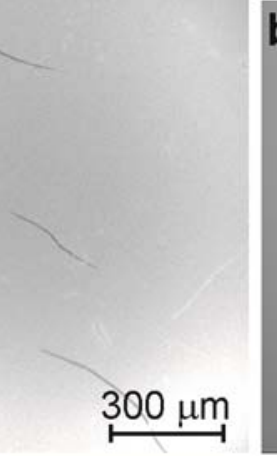

d)

$\stackrel{300 \mu \mathrm{m}}{\longmapsto}$

b)

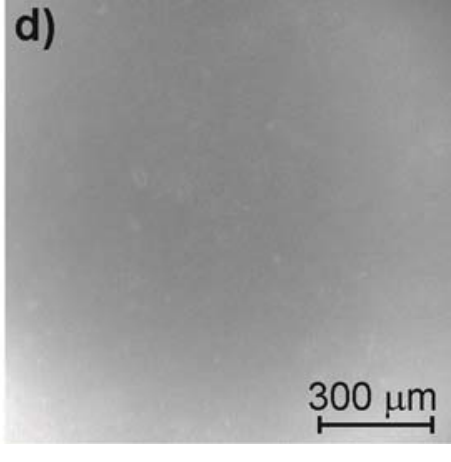

c)

$300 \mu \mathrm{m}$
$300 \mu \mathrm{m}$

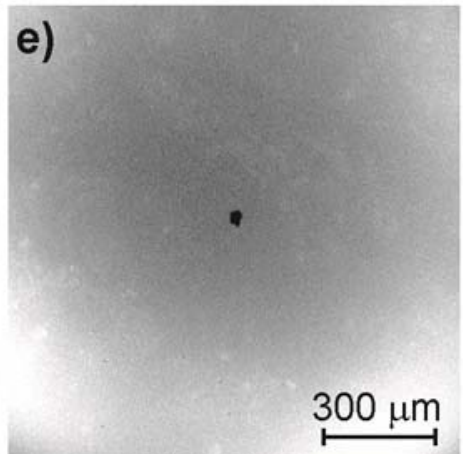

FIGURE 7. SEM images of polypropylene formulations with different flavonoids ( 0.5 wt.\%) subjected to UV light exposure for 3 h. a) PP + naringin, b) PP + chrysin, c) PP + hesperidin, d) PP + quercetin and e) PP + silibinin. 

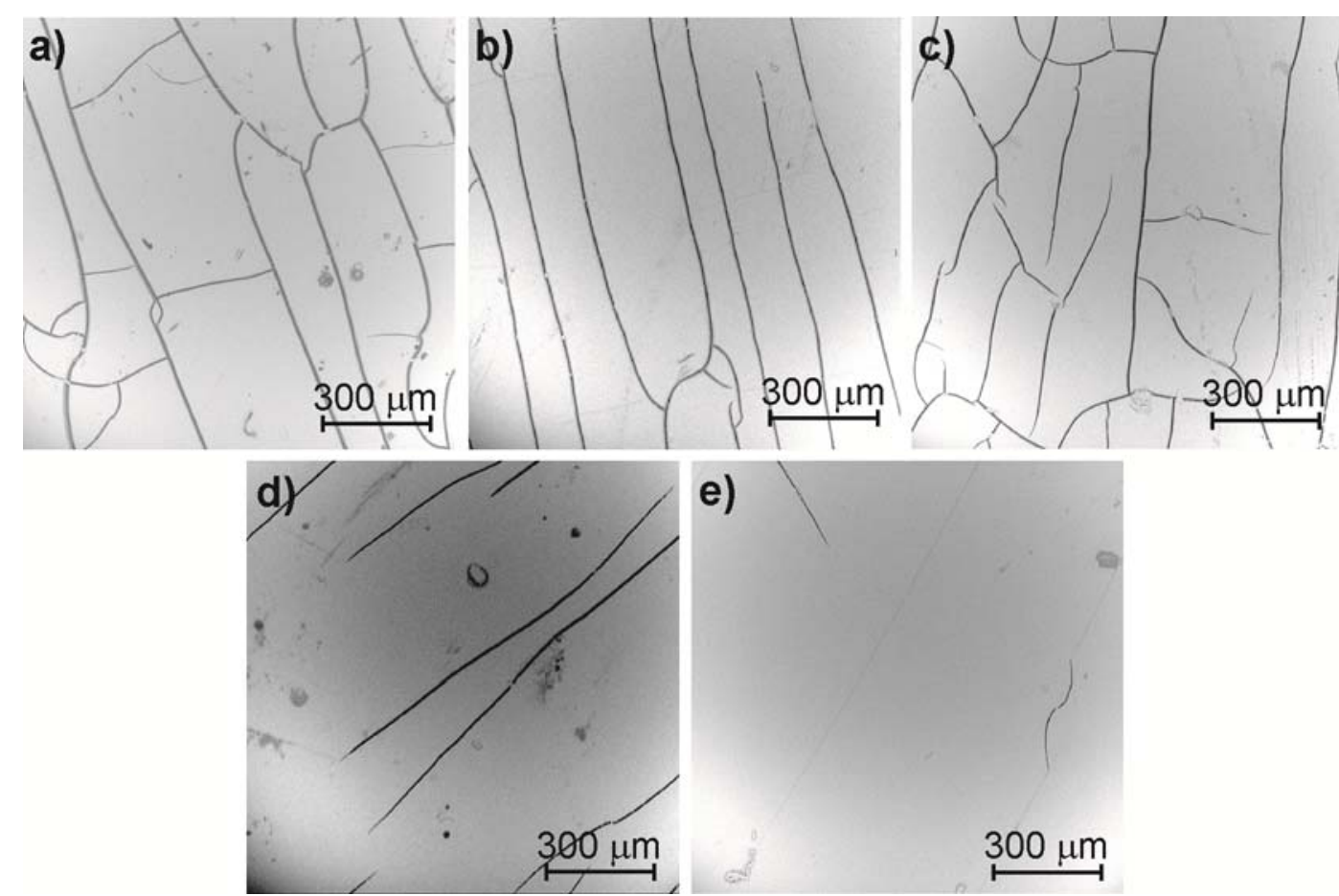

FIGURE 8. SEM images of polypropylene formulations with different flavonoids $(0.5$ wt.\%) subjected to UV light exposure for 5 h. a) PP + naringin, b) PP + chrysin, c) PP + hesperidin, d) PP + quercetin and e) PP + silibinin.

Table 1. Results of DSC dynamic characterization (TOnSet) and isothermal (tonset) of polypropylene formulations with quercetin and silibinin at different percentages $(0.25$; 0.5 and 0.75 wt.\%).

\begin{tabular}{lll}
\hline Sample & $\begin{array}{l}\mathrm{T}^{\mathrm{a}} \text { Onset }\left({ }^{\circ} \mathrm{C}\right) \\
\text { OOT }\end{array}$ & $\begin{array}{l}\text { t Onset }(\mathrm{min}) \\
\text { OIT }\end{array}$ \\
\hline PP & 226,4 & 8.0 \\
PP 0.25\%QUER & 263.8 & 77.1 \\
PP 0.5\% QUER & 259.8 & 81.4 \\
PP 0.75\% QUER & 264.8 & 94.3 \\
PP 0.25\% SIL & 238.3 & 16.9 \\
PP 0.5\% SIL & 249.7 & 16.7 \\
PP 0.75\% SIL & 245.8 & 84.0 \\
\hline
\end{tabular}


Table 2. Thermal degradation data obtained by TGA of polypropylene formulations with quercetin and silibinin at different percentages $(0.25 ; 0.5$ and $0.75 \mathrm{wt} . \%)$.

\begin{tabular}{lll}
\hline Sample & $\mathrm{T}^{\mathrm{a}}$ Onset $\left({ }^{\circ} \mathrm{C}\right)$ & Inft Point $\left({ }^{\circ} \mathrm{C}\right)$ \\
\hline PP & 265.9 & 338.7 \\
PP 0.25\%QUER & 301.1 & 391.5 \\
PP 0.5\% QUER & 287.1 & 363.5 \\
PP 0.75\% QUER & 298.0 & 380.6 \\
PP 0.25\% SIL & 282.9 & 376.2 \\
PP 0.5\% SIL & 289.0 & 367.7 \\
PP 0.75\% SIL & 310.8 & 402.9 \\
PP 0.5\% NAR & 276.8 & 341.4 \\
PP 0.5\% CHRY & 278.9 & 357.1 \\
PP 0.75\% HESP & 265.1 & 324.2 \\
\hline
\end{tabular}

Table 3. FTIR results of the UV light aging. Evolution of the carbonyl peak for polypropylene formulations with $0.5 \mathrm{wt} . \%$ of different flavonoids subjected to UV light aging.

\begin{tabular}{llllll}
\hline Sample & $\begin{array}{l}\text { Carbonyl } \\
\text { index }(\mathrm{t}=0 \mathrm{~h})\end{array}$ & $\begin{array}{l}\text { Carbonyl } \\
\text { index }(\mathrm{t}=2 \mathrm{~h})\end{array}$ & $\begin{array}{l}\text { Carbonyl } \\
\text { index }(\mathrm{t}=3 \mathrm{~h})\end{array}$ & $\begin{array}{l}\text { Carbonyl } \\
\text { index }(\mathrm{t}=5 \mathrm{~h})\end{array}$ & $\begin{array}{l}\text { Carbonyl } \\
\text { index }(\mathrm{t}=6 \mathrm{~h})\end{array}$ \\
\hline PP & $8.6 \times 10^{-2}$ & $12.9 \times 10^{-2}$ & $22.7 \times 10^{-2}$ & $26.8 \times 10^{-2}$ & $28.8 \times 10^{-2}$ \\
PP NAR & $7.1 \times 10^{-2}$ & $8.5 \times 10^{-2}$ & $19.8 \times 10^{-2}$ & $24.3 \times 10^{-2}$ & $28.7 \times 10^{-2}$ \\
PP CHRY & $5.1 \times 10^{-2}$ & $14.9 \times 10^{-2}$ & $25.3 \times 10^{-2}$ & $26.9 \times 10^{-2}$ & $29.1 \times 10^{-2}$ \\
PP HESP & $9.9 \times 10^{-2}$ & $12.4 \times 10^{-2}$ & $18.6 \times 10^{-2}$ & $20.6 \times 10^{-2}$ & $30.9 \times 10^{-2}$ \\
PP QUER & $6.1 \times 10^{-2}$ & $13.4 \times 10^{-2}$ & $15.7 \times 10^{-2}$ & $17.6 \times 10^{-2}$ & $25.4 \times 10^{-2}$ \\
PP SIL & $9.6 \times 10^{-2}$ & $16.2 \times 10^{-2}$ & $17.6 \times 10^{-2}$ & $18.6 \times 10^{-2}$ & $25.2 \times 10^{-2}$ \\
\hline
\end{tabular}

Table 4. DSC results of the UV light aging. Evolution of the crystallinity for polypropylene formulations with $0.5 \mathrm{wt} . \%$ of different flavonoids subjected to UV light aging.

\begin{tabular}{lcccccc}
\hline Sample & $\begin{array}{c}X_{\mathrm{c}}(\%) \\
(\mathrm{t}=0 \mathrm{~h})\end{array}$ & $\begin{array}{c}X_{\mathrm{c}}(\%) \\
(\mathrm{t}=2 \mathrm{~h})\end{array}$ & $\begin{array}{c}X_{\mathrm{c}}(\%) \\
(\mathrm{t}=3 \mathrm{~h})\end{array}$ & $\begin{array}{r}X_{\mathrm{c}}(\%) \\
(\mathrm{t}=5 \mathrm{~h})\end{array}$ & $\begin{array}{r}X_{\mathrm{c}}(\%) \\
(\mathrm{t}=6 \mathrm{~h})\end{array}$ & $\Delta X_{\mathrm{c}}(\%)$ \\
\hline PP & 34.10 & 34.96 & 39.13 & 40.94 & 44.60 & 10.50 \\
PP NAR & 37.66 & 40.61 & 41.48 & 44.20 & 57.83 & 20.17 \\
PP CHRY & 35.47 & 40.38 & 40.87 & 42.12 & 50.40 & 14.93 \\
PP HESP & 34.95 & 35.15 & 41.16 & 41.74 & 50.13 & 15.17 \\
PP QUER & 43.66 & 43.77 & 44.57 & 45.60 & 45.81 & 2.14 \\
PP SIL & 39.29 & 42.54 & 43.05 & 44.78 & 45.84 & 6.55 \\
\hline
\end{tabular}


